\title{
Quality characteristics of extracted oil from the head and gills of Catfish and Titus fish
}

\author{
Oluseye Oladapo Abiona ${ }^{1 *} \mathbb{D}$, Shola Hezekiah Awojide ${ }^{2}$, Adebanjo Jacob Anifowose², \\ Abiodun Odunlami Adegunwa ${ }^{2}$, Wasiu Bolade Agbaje ${ }^{2}$ and Adeniyi Solomon Tayo ${ }^{2}$
}

\begin{abstract}
Background: The research was carried out to assess the lipid characteristics of oil extracted from the head and gills of Claris macrocephalus and Scomber scombrus.

Results: The results confirmed the presence of C16:0, C18:0, C18:1, C18:2, C18:3, C22:6 as the major fatty acids. Titus fish head (TFHD) oil had a total saturated fatty acid (TSFA) of $40.804 \pm 0.002 \%$ of which C16:0 and C18:0 were the most dominant fatty acids present while the total monounsaturated fatty (TMUFA) acids present in the oil was $33.853 \pm 0.001 \%$. The total polyunsaturated fatty acid (TPUFA) content of the TFHD oil sample was found to be $25.368 \pm 0.002 \%$. The results revealed that the total unsaturated fatty acid (TUFA) present in the TFHD was higher than the TSFA. The results obtained for Titus fish gills (TFGL) oil sample followed the same trend as observed in the head sample. The results showed that the four (4) oil samples contain high level of palmitic acid (C16:0) and stearic acid (C18:0) both of which are saturated fatty acids (SFA). The main MUFA identified was C18:1 (cis-6) and ranged from $14.120 \pm 0.004$ to $20.418 \pm 0.002 \%$ for TFHD, TFGL, CFHD, CFGL and oleic acid (C18:1) ranged from $10.297 \pm 0.001$ to $11.570 \pm 0.003 \%$ for TFHD, TFGL, CFHD and CFGL.
\end{abstract}

Conclusions: Oils of CFHD and TFHD showed higher peroxide values indicating suitability for human consumption. Keyword: Fish head, Fish gills, Fatty acids, Claris macrocephalus, Scomber scombrus

\section{Background}

The consumption of fish has attracted a lot of attention from scientists as it is an essential part in the diet of the world owing to its reliability as a source of nutrient in food. Fatty acids and protein which is the main components in fish has not only delivered direct nutrients but also as constituents of remedial process in various wellness conditions. The oil from fish has been seen to avail prominent health benefits to the users owing to the availability of omega-3 polyunsaturated fatty acid (PUFA) such as eicosapentaenoic acid (EPA) and docosahexaenoic acid.

\footnotetext{
*Correspondence: oluseye.abiona@uniosun.edu.ng

${ }^{1}$ Department of Food Science and Technology, Osun State University,

P.M.B. 4494, Osogbo, Osun State, Nigeria

Full list of author information is available at the end of the article
}

Fish are cold-blooded animals with scaly streamlined bodies. Fish play essential role in the world as animal feeds, fertilizers and foods. They are special in the human chain due to their nutritive components such as protein, vitamin (A, B and D) minerals namely calcium, phosphorus, iodine, and lipids (United States Department of Agriculture 2011). Fatty acids are long hydrocarbon chain capped by a carboxyl group $(-\mathrm{COOH})$. The hydrocarbon chain length may vary from 10 to 30 carbons (most usual is 12-18). They are acids produced when fats are broken down. They are considered "good fats". Fatty acids are important components of lipids (fat-soluble components of living cells) in plants, animals, and microorganisms. The consumption of fish has attracted a lot of attention from scientists as it is an essential part in the diet of the world owing to its reliability as a source of nutrient in food. Fatty acids and protein which is the main components in fish has not only delivered direct nutrients but 
also as constituents of remedial process in various wellness conditions. The oil from fish has been seen to avail prominent health benefits to the users owing to the availability of omega-3 polyunsaturated fatty acid (PUFA) such as eicosapentaenoic acid (EPA) and docosahexaenoic acid (DHA) (Minis et al. 2006). Oily and fish oil supplements help in the determent and control of Coronary Heart Disease (CHD) (Inga-Britt et al. 2004). Carried out a research on seafood products rich in omega-3-fatty acid and deduced their effectiveness and efficiency in reducing serum triglycerides and pressure of the circulating blood against the walls of the blood vessels. They assist in ameliorating the risk of developing an abnormal heartbeat which can escalate to heart problems, thus leading to sudden death. The significance of fatty acids in fish cannot be overemphasized since their ingestion as food aids the reduction in cardiovascular diseases (Nordøy et al. 2001; Turkmen et al. 2005).

In Nigeria, the family Clarinda of catfishes has developed adaptivity to nearly all parts of the country with a constant rise in its culture in the last decades (Oresegun et al. 2007). This is mainly due to the eco-friendly nature of these species in addition to its resistance to unpropitious conditions.

In the processing of catfish, the by-products consist of frames and viscera which are often disposed away during conditioning. Lipids could be sourced from catfish viscera rather than discarding it as waste (Sathivel et al. 2003). A large number of total fish catch is wasted as remains from processing; these could include trimmings, fins, frames, head and Viscera. Some of the byproducts are transformable into usable products but the massive bulk of it is dumped, thereby causing, not only disposal problems, but also environmental impureness. The knowledge of these chemical characteristics and fatty acids is critical to final quality of products gotten from the oil. This study was designed to assess the quality of the lipid characteristics of oil obtained from the head and gills of the two species of fish common in Nigeria in order to enlighten the wide consumers of oils of the benefits derived from fish waste.

\section{Methods \\ Materials}

The fishes used in this study were bought from Oke-baale Market Osogbo, Osun State, Nigeria. Two species of fish, catfish (Claris macrocephalus) and Titus fish (Scomber scombrus), were bought.

\section{Preparation of samples for analysis}

Ten grams (10 g) of the gills and heads obtained from each fish were transferred to an oven for it to be dried to a considerable moisture level. The fish samples were then grinded using a mortar and pestle.

\section{Extraction of oil from fish samples}

Finely ground fish $(5 \mathrm{~g})$ (particle size $=2 \mathrm{~mm}$ ), were used to obtain oil by Soxhlet extraction using $n$-hexane for $6 \mathrm{~h}$. The rotary evaporator was used to remove solvent at $40{ }^{\circ} \mathrm{C}$. The oil was dried by nitrogen streaming and stored at $20{ }^{\circ} \mathrm{C}$ for further analysis.

\section{Chemical analysis on samples}

Free Fatty Acid, Iodine Value, Saponification Value, Peroxide Value, Thiobarbituric Acid (TBA) Value and Acid Value were all determined by the methods of AOAC (2005).

\section{Fatty acid composition (FAC)}

A gas chromatograph (model 8700; Perkin Elmer), fitted with a capillary column SP-2340 polar $(60 \mathrm{~m} \times 0.25 \mathrm{~mm})$, and FID (flame ionization detector). As a carrier gas, nitrogen (oxygen free) was used at a flow rate of $3.5 \mathrm{~mL} /$ min. Injector temperature: $260{ }^{\circ} \mathrm{C}$; detector temperature: $270{ }^{\circ} \mathrm{C}$, initial oven temperature: $130{ }^{\circ} \mathrm{C}$; and final temperature: $220^{\circ} \mathrm{C}$ with ramp rate: $4{ }^{\circ} \mathrm{C} / \mathrm{min}$. A sample volume of $2.0 \mu \mathrm{L}$ was injected. Fatty acid methyl esters quantification and identification was carried out by comparing the retention time of peak area with those of pure standards purchased from Sigma Chemical Co (St. Louis, MO, USA), under the same conditions. In lipid fraction the results were expressed as a percentage of individual fatty acids.

\section{Results}

Table 1 presents the Fatty acid profile of oil extracted from gills and head of Cat fish (Claris macrocephalus) and Titus fish (Scomber scombrus). From the Table, it was observed that a total of about 20 components were determined from the four (4) samples of which palmitic acid had the highest composition (C16:0) which ranged from $27.499 \%$ in TFHD to $34.160 \%$ in TFGL, followed by oleic (C18:1) which ranged from $24.427 \%$ in TFHD to $31.988 \%$ in CFGL.

From Table 1, TFGL had the highest total saturated fatty acid (TSFA) of $45.364 \%$ while CFHD had the lowest composition of total saturated fatty acid with a value of $40.005 \%$. The most dominant saturated fatty acid present is palmitic acid with a percentage composition of 27.499\%. Total monounsaturated fatty (TMUFA) ranged between 33.853 and $42.326 \%$. TFGL with a composition of $42.326 \%$ had the highest composition of MUFA.

From Table 1, it can also be seen that CFHD had the highest composition of the total polyunsaturated fatty acid of $25.643 \%$ while TFGL had the least composition 
Table 1 Fatty acid profile of oil extracted from gills and head of Catfish and Titus fish

\begin{tabular}{|c|c|c|c|c|}
\hline \multicolumn{5}{|c|}{ \%Composition } \\
\hline Components & TFHD & TFGL & CFHD & CFGL \\
\hline C12:0 & $0.406 \pm 0.001^{a}$ & $0.412 \pm 0.003^{\mathrm{a}}$ & $0.612 \pm 0.002^{a}$ & $0.093 \pm 0.001^{a}$ \\
\hline C14:0 & $2.625 \pm 0.001^{\mathrm{a}}$ & $2.434 \pm 0.002^{\mathrm{a}}$ & $3.484 \pm 0.001^{\mathrm{a}}$ & $2.249 \pm 0.003^{a}$ \\
\hline C16:0 & $27.499 \pm 0.002^{\mathrm{a}}$ & $34.160 \pm 0.003^{\mathrm{a}}$ & $27.696 \pm 0.001^{\mathrm{a}}$ & $30.548 \pm 0.002^{\mathrm{a}}$ \\
\hline C18:0 & $10.196 \pm 0.002^{\mathrm{a}}$ & $8.256 \pm 0.003^{a}$ & $8.170 \pm 0.001^{a}$ & $9.800 \pm 0.001^{a}$ \\
\hline C20:0 & $0.026 \pm 0.002^{\mathrm{a}}$ & $0.050 \pm 0.001^{\mathrm{a}}$ & $0.021 \pm 0.001^{a}$ & $0.037 \pm 0.002^{a}$ \\
\hline C22:0 & $0.024 \pm 0.002^{\mathrm{a}}$ & $0.046 \pm 0.001^{\mathrm{a}}$ & $0.020 \pm 0.001^{a}$ & $0.034 \pm 0.003^{a}$ \\
\hline C24:0 & $0.003 \pm 0.001^{\mathrm{a}}$ & $0.006 \pm 0.002^{\mathrm{a}}$ & $0.002 \pm 0.001^{a}$ & $0.004 \pm 0.000^{a}$ \\
\hline C14:1 & $0.003 \pm 0.001^{b}$ & $0.006 \pm 0.002^{b}$ & $0.003 \pm 0.002^{b}$ & $0.005 \pm 0.001^{b}$ \\
\hline C16:1 & $3.927 \pm 0.003^{b}$ & $4.446 \pm 0.001^{b}$ & $4.312 \pm 0.001^{b}$ & $3.255 \pm 0.002^{b}$ \\
\hline C18:1 & $24.427 \pm 0.001^{b}$ & $31.018 \pm 0.001^{b}$ & $24.308 \pm 0.002^{b}$ & $31.993 \pm 0.001^{b}$ \\
\hline C24:1 & $0.003 \pm 0.001^{b}$ & $0.006 \pm 0.002^{b}$ & $0.002 \pm 0.001^{b}$ & $0.004 \pm 0.003^{b}$ \\
\hline C18:2 & $3.016 \pm 0.003^{c}$ & $4.379 \pm 0.001^{c}$ & $2.933 \pm 0.002^{c}$ & $1.950 \pm 0.001^{c}$ \\
\hline C20:2 & $0.004 \pm 0.001^{c}$ & $0.007 \pm 0.003^{c}$ & $0.003 \pm 0.001^{c}$ & $0.005 \pm 0.001^{c}$ \\
\hline$C 22: 2$ & $0.359 \pm 0.002^{c}$ & $0.096 \pm 0.001^{c}$ & $0.181 \pm 0.003^{c}$ & $0.231 \pm 0.002^{c}$ \\
\hline C18:3 & $0.657 \pm 0.001^{c}$ & $0.839 \pm 0.002^{c}$ & $0.636 \pm 0.001^{c}$ & $1.130 \pm 0.002^{c}$ \\
\hline C20:3 & $0.016 \pm 0.003^{c}$ & $0.031 \pm 0.001^{c}$ & $0.013 \pm 0.002^{c}$ & $0.023 \pm 0.003^{c}$ \\
\hline C20:4 & $6.988 \pm 0.001^{c}$ & $1.910 \pm 0.002^{c}$ & $6.662 \pm 0.002^{c}$ & $1.494 \pm 0.001^{c}$ \\
\hline C20:5 & $3.633 \pm 0.002^{c}$ & $1.036 \pm 0.002^{c}$ & $6.512 \pm 0.001^{c}$ & $4.039 \pm 0.002^{c}$ \\
\hline C22:6 & $9.307 \pm 0.002^{c}$ & $1.619 \pm 0.001^{c}$ & $6.955 \pm 0.003^{c}$ & $5.872 \pm 0.002^{c}$ \\
\hline TSFA & $40.804 \pm 0.002$ & $45.364 \pm 0.002$ & $40.005 \pm 0.001$ & $42.765 \pm 0.003$ \\
\hline MUFA & $33.853 \pm 0.001$ & $42.326 \pm 0.003$ & $34.359 \pm 0.001$ & $40.733 \pm 0.002$ \\
\hline PUFA & $25.368 \pm 0.002$ & $12.313 \pm 0.001$ & $25.643 \pm 0.001$ & $13.513 \pm 0.003$ \\
\hline TUFA & $59.221 \pm 0.001$ & $54.639 \pm 0.001$ & $60.002 \pm 0.002$ & $57.246 \pm 0.002$ \\
\hline
\end{tabular}

Results expressed as average \pm standard deviation. Data within a row, followed by the same letter are not significantly different at $p<0.05$

$\mathrm{TFHD}=$ Titus fish head; $\mathrm{TFGL}=$ Titus fish gills; $\mathrm{CFHD}=$ Catfish head; $\mathrm{CFGL}=$ Catfish gills

of $12.313 \%$. Docosahexaenoic acid (C22:6) with a percentage composition of $9.307 \%$ was the most prominent polyunsaturated fatty acid present in the oil samples. It was also observed that the total unsaturated fatty acid (TUFA) present in the Titus fish head (TFHD) is higher than the total saturated fatty acid (TSFA). The result also revealed that the total unsaturated fatty acids was highest in CFHD with a compositional value of $60.002 \%$ but least in TFGL with a value of $54.639 \%$.

The total monounsaturated fatty acid (TMUFA) present in the cat fish head (CFHD) oil sample as seen in Table 1 was $34.359 \%$ with oleic acid (C18:1) having the most composition with $24.298 \%$. The most predominant polyunsaturated fatty acids (PUFA) found in the cat fish head (CFHD) sample were arachidonic acid (C20:4) with $6.662 \%$, eicosapentaenoic acid (C20:5) with $6.512 \%$ and docosahexaenoic acid (DHA) (C22:6) with 6.955\%. Arachidonic acid helps regulate Neuronal activity and also acts as a substrate that is changed to useful metabolites (Uauy and Valenzuela 2000). Eicosapentaenoic acid (EPA) is used in combination with docosahexaenoic acid (DHA) in fish oil preparation for a variety of conditions, including preventing and reversing heart diseases, and decreasing irregular heartbeats. This makes this oil sample (CFHD) of high nutritional value.

The total saturated fatty acid (TSFA) composition of lipid extracted from cat fish gills (CFGL) as shown in Table 1 was $42.765 \%$ with palmitic acid and stearic acid constituting the highest fatty acids with $30.548 \%$ and $9.800 \%$, respectively. Myristic acid with $2.249 \%$ was also found in a small quantity. Palmitic acid was the most abundant fatty acid present in this sample (CFGL) making it inedible due to its negative impact on the human health (Hunter et al. 2010).

The most abundant MUFA present in the CFGL oil sample was C18:1 with $31.988 \%$. Oleic acid was also present with a percentage composition of $11.570 \%$. The total MUFA present in CFGL amounted to $40.733 \%$ while the total PUFA present in this oil sample was $16.513 \%$ with eicosapentaenoic acid (C20:5) and docosahexaenoic acid (C22:6) the most visible fatty acids present with $4.039 \%$ and $5.872 \%$, respectively. Total unsaturated fatty acid (TUFA) present in the oil obtained from cat fish gills (CFGL) was $57.246 \%$. 
It was observed that all the four (4) oil samples contain high level of palmitic acid (C16:0) and stearic acid (C18:0) both of which are saturated fatty acids (SFA). The results revealed that oil obtained from Titus fish head (TFHD) had the highest composition of saturated fatty acids with $34.160 \%$ making it the most undesirable oil of all because saturated fatty acids are the major risk factor for heart attacks and strokes. They also cause cancer of the breast and colon (Hunter et al. 2010). Titus fish head (TFHD) oil sample had the least saturated fatty acid with a value of $27.499 \%$. Consumption of saturated fat increases levels of low-density lipoprotein (LDL) cholesterol. LDL cholesterol has been positively associated with cardiovascular disease (CVD) risk. This indicates that the oil gotten from Cat fish head (CFHD), if consumed regularly, accumulates in the body to cause detrimental effects to the human body. Stearic acid was associated with lowered LDL cholesterol in comparison with other saturated fatty acids (Hunter et al. 2010). The total monounsaturated fatty acids (MUFA) of the TFHD, TFGL, CFHD and CFGL according to Table 1 were determined to be $33.853 \%, 42.326 \%, 34.359 \%$ and $40.733 \%$, respectively. The major MUFA component identified was C18:1 which constituted $24.427 \%, 31.108 \%, 24.298 \%$ and $31.988 \%$ for TFHD, TFGL, CFHD and CFGL, respectively. The obtained results agreed with Mensik and Katan (1990), the highest composition of monounsaturated fatty acids (MUFAs) in samples of oil is associated with a decreased risk of coronary heart disease. Oil with high amount of MUFA induces a desirable effect on the health benefits. Hence, TFGL (42.326\%) and CFGL (40.733\%) have a tendency of reducing coronary heart disease.

Oleic acid (C18:1) may be responsible for the hypotensive (blood reducing) effects of olive oil and may hinder the progression of adrenoleuko dystrophy (ALD), a fatal disease that affects the brain and adrenal glands (Terés et al. 2008). Monounsaturated fatty acid levels in the membranes of red blood cells have been associated with increased risk of breast cancer (Barascu et al. 2006). Thus, consumption of oil gotten from TFGL and CFGL may hinder progression of ALD and since TFHD and CFGL have high values of MUFAs and oleic acids value, it is therefore associated with increased risk of breast cancer.

Table 2 shows the result obtained for the physiochemical properties of four (4) oils sample obtained from Titus fish head (TFHD), Titus fish gills (TFGL), Cat fish head (CFHD) and Cat fish gills (CFGL).

Oil sample from CFHD recorded the lowest saponification value of $185.5 \mathrm{mgKOH} / \mathrm{g}$ while oil from THGL had the highest value of $236.0 \mathrm{mgKOH} / \mathrm{g}$. The oil from Titus Fish were observed to record a higher saponification value than was obtainable in the case of Catfish oil, making them more suitable for soap production (Undeland 1998). The iodine value of $75.28 \mathrm{~g} / 100 \mathrm{~g}$ was the lowest iodine value recorded in the oil of THGL while the highest value of $85.20 \mathrm{~g} / 100 \mathrm{~g}$ was observed in CFGL. The oil samples of Catfish had a higher iodine value compared to those of Titus fish. Iodine number is often used to determine the amount of unsaturation in fatty acids. This unsaturation is in the form of double bonds, which react with iodine compounds. The higher the iodine number, the more $\mathrm{C}=\mathrm{C}$ bonds present in the fat. This simply means that iodine value is a measure of the degree of unsaturation that is widely used to characterize fats and oils.

This shows that CFGL has the highest iodine value indicating that the highest decrease in double bonds occurred due to oxidative rancidity in the sample. This observation could be due to the presence of a high value of total unsaturated fatty acid in the oil gotten from this sample. The greater the unsaturation or iodine value, the more rapid the oil tends to be oxidized (Gladyshev et al. 2006; Kim and Choe 2004), and hence, more oxidative rancidity occurred in oil gotten from the CFGL. Due to its high iodine value meanly it is highly unsaturated; oil gotten from CFGL makes for a drying oil well suited for making paints.

It must be noted that the iodine value of the waste lipids samples in this research showed lower amount than Fish flesh lipids such as sardines $\left(156.2 \mathrm{gI}_{2} / 100 \mathrm{~g}\right)$ and Tuna (162.0 $\left.\mathrm{gI}_{2} / 100 \mathrm{~g}\right)$ flesh (Undeland 1998). This difference

Table 2 Chemical quality index of oil extracted from gills and head of Catfish and Titus fish

\begin{tabular}{|c|c|c|c|c|c|c|}
\hline \multicolumn{7}{|c|}{ Parameters } \\
\hline Samples & $\begin{array}{l}\text { Saponification } \\
\text { (mgKOH/g of oil) }\end{array}$ & $\begin{array}{l}\text { Peroxide value } \\
(\mathrm{Meq} / \mathrm{kg})\end{array}$ & lodine value $(\mathrm{g} / 100 \mathrm{~g})$ & $\begin{array}{l}\text { Acid value } \\
\text { (mgKOH/g of oil) }\end{array}$ & FFA (oleic \%) & $\begin{array}{l}\text { TBA (mg } \\
\text { malonaldehyde } \\
/ \mathrm{kg} \text { ) }\end{array}$ \\
\hline TFHD & $228.00 \pm 9.11$ & $3.91 \pm 0.10$ & $78.00 \pm 1.21$ & $6.25 \pm 0.67$ & $3.68 \pm 0.42$ & $1.42 \pm 0.01$ \\
\hline THGL & $236.00 \pm 3.24$ & 4.240 .20 & $75.28 \pm 3.20$ & $5.92 \pm 0.77$ & $3.40 \pm 0.44$ & $1.38 \pm 0.01$ \\
\hline CFHD & $175.40 \pm 1.21$ & $2.53 \pm 0.21$ & $81.40 \pm 3.02$ & $6.19 \pm 0.54$ & $3.67 \pm 0.10$ & $1.32 \pm 0.02$ \\
\hline CFGL & $185.50 \pm 1.11$ & $2.60 \pm 0.23$ & $85.20 \pm 3.52$ & $3.25 \pm 0.38$ & $3.25 \pm 0.11$ & $1.29 \pm 0.01$ \\
\hline
\end{tabular}

FFA = free fatty acids; TBA = 2-thiobarbituric acid value; TFHD = Titus Fish Head; TFGL = Titus Fish Gills; CFHD =Catfish Head; CFGL $=$ Catfish Gill 
may be attributed to different capture seasons, sex, maturity and different fish species and kind of sample.

Peroxide value (PV) is the measure of primary oxidation of oils (Bimbo and Crowther 1991). PV gives an extent to which an oil sample has undergone primary oxidation; Detection of peroxide value gives the initial evidence of rancidity in unsaturated fats and oil. Other methods are available but peroxide value is the most widely used. The double bonds found in fats and oil plays an important role in auto oxidation. Oils with a high degree of unsaturation are most susceptible to autoxidation. The best test for autoxidation (oxidative rancidity) is determination of PV (Gladyshev et al. 2006).

\section{Discussion}

Generally, it was observed that that TFGL has the lowest amount of polyunsaturated fatty acids (PUFA) (12.313\%) compared to CFHD (25.643\%) which has the highest amount. Systematic and scientific research have established docosahexaenoic acid (DHA) - an omega-3 fatty acid commonly domicile in fish oil is indispensable for the maturation of the premature infant analogous to sharpness of vision, visual function and development to maturity (Innis 2004). FTHD was found to have the highest amount of DHA with 9.307\% while TFGL was found to have the lowest amount with $1.619 \%$. In the full term infant, DHA may have impact on sharpness of vision and nerve cells responsible for promoting progression of language acquisition. The highly unsaturated fatty acids (HUFAs); eicosapentaenoic acid C20:5) and docosahexaenoic acid (C22:6) ingestion is equally linked to the advancement of brain and nervous tissue in infants and curtails prevalence of coronary heart disease (Uauy et al. 2001; Jiang et al. 1998; Bucher et al. 2002). These outcome of the findings have led to the admittance of DHA, arachidonic (AA) (C20:4), an omega-6 fatty acid, and eicosapentaenoic acid, an omega-3 fatty acid (All PUFAs) in infant formula by most countries around the world. Some properties of PUFAs make them attractive options in the treatment of cancer (Garcia et al. 2004). Arachidonic acid (C20:4) is also a precursor of prostaglandin and thromboxane.

Polyunsaturated fatty acids (PUFAs) have been found to moderate cell membrane phospholipids, remodel cellular functions which have propensity of lessening tumor motile/invasive potential which is inimical to tumor cells, regulate the sensitivity of tumor cells to chemotherapeutic agents and to radiate and avail a safeguarding role towards normal tissue (in radiation). CFHD and TFHD both have the high amount of PUFA will be suitable for cancer reduction (Osman et al. 2001).

It should be noted that the total unsaturated fatty acid (TUFA) in all of the oil samples was greater than that of the total saturated fatty acid (TSFA). Also fatty acid composition of head and gills of Cat fish (Claris macrocephalus) and Titus fish (Scomber scombrus) showed high content of palmitic acid and oleic acid. These findings are in agreement with what was reported by Garcia et al. (2004) and Osman et al. (2001). In general, the lower the PV of a sample, the better the quality of the oil. However, PV decreases as secondary oxidation products appear. From Table 2, peroxide value ranged from 2.60 to $4.24 \mathrm{meq} / \mathrm{kg}$ with CFGL having the lowest peroxide value, which revealed that minimum amount of autoxidation, occurred in the sample. Oil sample from TFGL recorded the highest PV indicating it is very prone to rancidity. This means that the oil obtained from Catfish gills (CFGL) had the best oil quality. The free fatty acid (FFA) value is one of the most important factors to check the lipid quality. The lower FFA content shows higher quality and lower further oxidation. These FFA exist in their free state and they are known to get oxidized faster than the fatty acids that are esterifies. This means that FFA can constitute problem to the consumer with time and they are obtained by hydrolysis which occur during heating. CFGL had the lowest free fatty acid value (3.25\%) while TFHD has the highest free fatty acid value (3.6\%). The values of the FFA in all samples are not significantly different. Bimbo and Crowther (1991) reported that the maximum limit for free fatty acid content in lipid is $7 \%$, since the values of FFA obtained from all samples are lower than this value, they can be said to be less harmful to man. Acid value ranged from 5.92 to $6.64 \mathrm{mgKOH} / \mathrm{g}$ with TFGL having the lowest acid value and CFGL having the highest. The 2-thiobarbituric (TBA) value is a method to investigate secondary oxidative aldehyde products, usually in PUFA. The TBA test is unsuitable for complex food and biological systems. The test is not specific and can interact with other non-oil minor components (DNA, sugars). From Table 2, it was observed that the TBA value ranges from 1.29 to $1.42 \mathrm{mg}$ malonaldehyde/kg with CFGL having the lowest and TFHD having the highest value.

\section{Conclusions}

The result of this investigation revealed that the values recorded for the total unsaturated fatty acid (TUFA) is higher than that of the saturated fatty acid (SFA) which suggest that oil extracted from head and gills of the studied fish (Claris macrocephalus and Scomber scombrus) are edible and nutritionally good for human consumption. The lower PV and FFA values observed in CFGL is an indication of reduced autooxidation which help promote good condition of heart, this is as confirmed by the FFA value. In addition, the two fish visceral waste examined recorded a high amount of PUFA which have capacity for cancerous growth inhibition while palmitic and oleic acids presented considerably high concentration signifying quality of the oil health wise. Hence, the oil obtained from the studied fish waste is considered as a 
good nutrient source for human consumption with viable industrial application. In this sense, the financial benefits of the examined fish waste can be explored on a large scale and can as well reduce the amount of accumulated environmental waste.

\section{Abbreviations}

TFHD: Titus fish head; TSFA: Total saturated fatty acid; TMUFA: Total monounsaturated fatty acids; TPUFA: Total polyunsaturated fatty acids; TFGL: Titus fish gill; CFHD: Clarias fish head; CFGL: Clarias fish gill; TBA: Thiobarbituric acid; FAC: Fatty acid composition; DHA: Docosahexaenoic acid; MUFA: Polyunsaturated fatty acids; PUFA: Polyunsaturated fatty acids; SFA: Saturated fatty acid; PV: Peroxide value; FFA: Free fatty acid; LDL: Low-density lipoprotein.

\section{Acknowledgements}

Not applicable.

\section{Authors' contributions}

$\mathrm{AOO}, \mathrm{ASH}$ and AOA designed the study, carried out the research and wrote the manuscript draft. AAJ, AWB and TAS contributed to the study design, analyses and manuscript editing. All authors read and approved the final manuscript.

\section{Funding}

Not applicable.

\section{Availability of data and materials}

Not applicable.

\section{Declarations}

Ethics approval and consent to participate

Not applicable.

\section{Consent for publication}

Not applicable.

\section{Competing interests}

The authors declare that they have no competing interests.

\section{Author details}

'Department of Food Science and Technology, Osun State University, P.M.B. 4494, Osogbo, Osun State, Nigeria. ${ }^{2}$ Department of Pure and Applied Chemistry, Osun State University, P.M.B. 4494, Osogbo, Osun State, Nigeria.

Received: 13 April 2021 Accepted: 18 May 2021

Published online: 02 June 2021

\section{References}

AOAC (2005) Official methods of analysis of the association of analytical chemist,13th ed. William Horwitzed, Washington, pp 56-132

Barascu A, Besson P, Floch OL, Bougnoux P, Jourdan ML (2006) CDK1-cyclin B1 mediates the inhibition of proliferation induced by omega- 3 fatty acids in MDA MB- 231 breast cancer cells. Int J Biochem Cell Biol 38:196-208. https://doi.org/10.1016/j.biocel.2005.08.015

Bimbo AP, Crowther JB (1991) Fish oil: processing beyond crude oil. INFOFISH Int 6(91):20-25. https://doi.org/10.1590/1678-457X.6477

Bucher HC, Hengstler P, Schindler C, Meier G (2002) N-3 polyunsaturated fatty acids in coronary heart disease: a meta-analysis of randomized controlled trials. Am J Med 112:298-304. https://doi.org/10.1016/s0002-9343(01) 01114-7

Garcia GN, Aguilar RP, Alvarado LB, Garcia JO (2004) Characterization of the lipid composition and natural antioxidants in the liver oil of Dasyatis brevis and Gymnura marmorata rays. Food Chem 87:89-96. https://doi. org/10.1016/j.foodchem.2003.10.023

Gladyshev MI, Sushchik NN, Gubanenko GA, Demirchieva SM, Kalachova GS (2006) Effect of way of cook on content of essential fatty acids in muscle tissue of humpback salmon (Oncorhynchus gorbuscha). Food Chem 96(3):446-451. https://doi.org/10.1016/j.foodchem.2005.02.034

Hunter JE, Zhang J, Kris-Etherton PM (2010) Cardiovascular disease risk of dietary stearic acid compared with trans, other saturated and unsaturated fatty acids: a systematic review. Am J Clin Nutr 91(1):46-63. https:// doi.org/10.3945/ajcn.2009.27661

Inga-Britt GO, Margaretta BOE, Bergt V (2004) Moderate amounts of N-3 fully acid enriched seafood products. J Hum Nurt Diet 17:490-499. https://doi. org/10.1046/j.1365-277X.1996.00447.x

Innis SM (2004) Polyunsaturated fatty acids in human milk: an essential role in infant development. Adv Exp Med Biol 554:27-43. https://doi.org/10. 1007/978-1-4757-4242-8_5

Jiang WG, Bryce RP, Horrobin DF (1998) Essential fatty acids: molecular and cellular basis of their anti-cancer action and clinical implications. Crit Rev Oncol Hematol 27:179-209. https://doi.org/10.1016/s1040-8428(98) 00003-1

Kim I, Choe E (2004) Oxidative stability and antioxidant content changes in roasted and bleached sesame oil during heating. Food Sci Biotechnol 13:762-767

Mensik RP, Katan MB (1990) Effect of dietry trans-fatty acids on high density lipoprotein cholesterol levels in healthy subjects. N Engl J Med 323:439445. https://doi.org/10.1056/NEJM199008163230703

Minis R, Haq I, Jackson PR, Yeoad W, Ramsay L (2006) Oily fish and fish oil supplements in the prevention of coronary heart diseases. J Hum Nutr Diet 5:449-459. https://doi.org/10.1046/j.1365-277X.1998.00074.x

Nordøy A, Marchioli R, Arnesen H, Videbæk J (2001) N-3 Polyunsaturated fatty acids and cardiovascular diseases: to whom, how much, preparations. Lipids 36(S1):S127-S129. https://doi.org/10.1007/s11745-001-0695-7

Oresegun A, Oguntade OR, Ayinla OA (2007) A review of catfish culture in Nigeria. Nig J Fish 4(1):27-52

Osman A, Bagge CL, Guiterrez PM, Konick LC, Kopper BA, Barrios FX (2001) The Suicidal Behaviors Questionnaire-Revised (SBQ-R): validation with clinical and non-clinical samples. Assessment 8:445-455. https://doi.org/10. $1177 / 107319110100800409$

Sathivel S, Prinyawiwatkul W, Negulescu II, King JM, Basnayake BFA (2003) Thermal degradation of fatty acids and catfish and menhaden oils at different purification steps. J Am Oil Chem Soc 80(11):1131-1134. https://doi.org/ 10.1016/j.jfoodeng.2007.04.027

Terés S, Barceló-Coblijn G, Benet M, Álvarez R, Bressani R, Halver JE, Escribá PV (2008) Oleic acid content is responsible for the reduction in blood pressure induced by olive oil. PNAS 105(37):13811-13816. https://doi.org/10. 1073/pnas.0807500105

Turkmen A, Turkmen M, Tepe Y, Akyurt I (2005) Heavy metals in three commercially valuable fish species from Iskenderun bay, northern east, Mediterranean Sea, Turkey. Food Chem 91:167-172. https://doi.org/10. 1016/j.foodchem.2004.08.008

Uauy R, Valenzuela A (2000) Marine oils. The health benefits of $n-3$ fatty acids. Nutrition 16:680-684. https://doi.org/10.1016/s0899-9007(00)00326-9

Uauy R, Hoffman DR, Peirano P, Birch DG, Birch EE (2001) Essential fatty acids in visual and brain development. Lipids 36(9):885-895. https://doi.org/10. 1007/s11745-001-0798-1

Undeland I (1998) Investigation of antioxidant stability in herring fillets during ice storage. In: Final report of the concerted action "Evaluation of fish freshness" AIR3CT94 2283,December 1997-April 1998, G. Ólafsdóttir and E. Martinsdóttir (eds) Icelandic fisheries laboratories, Reykjavík, Report IFL 12, Appendix 4, pp 1-13

United States Department of Agriculture (2011) Nutrient data for 15067, Fish, Pollock, walleye, cooked, dry heat. USDA National Nutrient Database for Standard Reference. Release 24. Archived from the original on 5 January 2014. Retrieved 22 July2012

\section{Publisher's Note}

Springer Nature remains neutral with regard to jurisdictional claims in published maps and institutional affiliations. 